Original Article

\title{
Reproducibility and validity of the 50-meter walking test in community-dwelling elderly
}

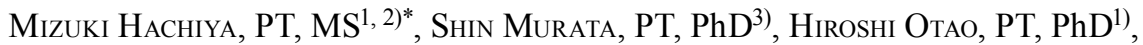 \\ Kenji Kamijou, OT, $\mathrm{PhD}^{1)}$, Katsuhiko Mizota, PT, $\mathrm{MS}^{1)}$, Toyoko Asami, MD, $\mathrm{PhD}^{2)}$ \\ 1) Faculty of Rehabilitation Science, Nishikyushu University: 4490-9 Ozaki, Kanzaki, Saga 842-8585, \\ Japan \\ 2) Graduate School of Medicine, Saga University, Japan \\ 3) Faculty of Health Science, Kyoto Tachibana University, Japan
}

\begin{abstract}
Purpose] This study aimed to investigate the reproducibility and validity of the 50-m walking test. [Subjects] Reproducibility was investigated in 19 community-dwelling elderly women (mean age, 76.3 years), and validity was investigated in 31 community-dwelling elderly individuals (12 men and 19 women; mean age, 75.7 years). [Methods] The time taken to walk $50 \mathrm{~m}$, the time taken to walk each $10-\mathrm{m}$ section (laps 1-5), the time taken to walk $10 \mathrm{~m}$, and grip strength were measured. In addition, the functional reach test (FRT), one-leg standing test, and timed up and go (TUG) test were performed. [Results] In a reproducibility analysis, the interclass correlation coefficient $(1,1)$ was 0.97 . In a Bland-Altman analysis, no systematic error was found. The measured values from the 50-m walking test included a measurement error of $1.5 \mathrm{~s}$, and the acceptable margin of error was confirmed to be $3.1 \mathrm{~s}$. In a validity analysis, the $50-\mathrm{m}$ walking test score was significantly correlated with the $10-\mathrm{m}$ walking and TUG test scores. [Conclusion] Our results suggest that the $50-\mathrm{m}$ walking test score may be a useful index of the walking ability of community-dwelling elderly.

Key words: 50 -meter walk test, Reproducibility, Validity
\end{abstract}

(This article was submitted Dec. 10, 2014, and was accepted Jan. 20, 2015)

\section{INTRODUCTION}

Many studies on walking have been performed. Walking ability can be assessed by having a subject walk a specified distance in a straight line, and recording the time required and walking speed. Previous studies have shown that walking ability is associated with factors such as activities of daily living and balance ${ }^{1,2)}$, and that walking speed measurements are highly reproducible ${ }^{3)}$. Walking speed slows with advancing age ${ }^{4)}$ and is known to contribute to the survival of elderly people ${ }^{5}$. Measurement of walking speed is a highly versatile assessment method because reference values are available for different age groups ${ }^{4}$ ) and it is simple and easy to execute.

Studies have suggested, however, that $10-\mathrm{m}$ walking time may not be a good measure of the endurance or balance of healthy elderly people ${ }^{6}$. The relationship between walking speed and leg muscle strength is also nonlinear ${ }^{7)}$. If leg muscle strength decreases at the same rate as walking speed, an association will be evident between them. In people with normal walking ability, however, walking speed does not

*Corresponding author. Mizuki Hachiya (E-mail:

hachiyami@nisikyu-u.ac.jp)

C2015 The Society of Physical Therapy Science. Published by IPEC Inc. This is an open-access article distributed under the terms of the Creative Commons Attribution Non-Commercial No Derivatives (by-ncnd) License $<$ http://creativecommons.org/licenses/by-nc-nd/3.0/> . reflect an improvement in leg muscle strength. This suggests that although short-distance walking tests over 5 or $10 \mathrm{~m}$ may be useful for assessing the walking ability of people with disorders or the frail elderly, they may not provide an appropriate assessment of physical function in healthy elderly people.

Hachiya et al. ${ }^{6}$ developed the 50 -m walking test to assess walking ability in the elderly and investigated the feasibility of its use for elderly people in local gatherings for testing physical fitness (tairyoku sokutei kai). They confirmed that the 50-m walking test was highly associated with quadriceps muscle strength, and the 30-second chair stand (CS-30), one-leg standing, and timed up and go (TUG) test scores. In addition, 5-m walking time has been confirmed to be associated with quadriceps muscle strength and TUG test score, but not with CS-30 and one-leg standing test scores. The reproducibility of the 50-m walking test, however, has yet to be established. If the types of error in the measurements and their acceptable margins were to be ascertained, this method might offer a valuable assessment tool.

This study aimed to describe the measurement method used in the 50-m walking test and to investigate its criterionrelated validity.

\section{SUBJECTS AND METHODS}

The study subjects were community-dwelling elderly people who were voluntary participants in a dementiaprevention project. The subjects of the reproducibility 
analysis for the 50-m walking test were 19 women (age, 76.3 \pm 5.7 years; height, $148.8 \pm 6.3 \mathrm{~cm}$; weight, $49.6 \pm 8.6 \mathrm{~kg}$; all the data are presented as mean \pm standard deviation values). The subjects of the validity analysis for the $50-\mathrm{m}$ walking test were 31 individuals (12 men and 19 women; age, $75.7 \pm 6.0$ years; height, $153.6 \pm 9.1 \mathrm{~cm}$; weight, 53.8 $\pm 9.9 \mathrm{~kg}$ ). Individuals with neurological or joint disorders who required treatment were excluded. The subjects were independent to the extent that they were able to participate in the study by themselves, arriving in their own vehicles or by passenger bus.

In terms of ethical considerations, informed consent was obtained from the subjects before measurements were started. This study was approved by the Study Group for Promoting Healthy Longevity in Imari, Japan.

In addition to the 50-m walking test, walking ability was also assessed in terms of the $10-\mathrm{m}$ walking test. Physical function was assessed by means of grip strength, the functional reach test (FRT), one-leg standing test, and timed up and go (TUG) test.

The $50-\mathrm{m}$ walking test was performed by having the subjects walk 2.5 return journeys between two cones placed $10 \mathrm{~m}$ apart along a walking course, for a total of $50 \mathrm{~m}$ (Fig. 1). The time taken to complete $50 \mathrm{~m}$ was measured by using a stopwatch. The items required were markers (cones) indicating where to change direction and a stopwatch with a lap time function. Before the start of measurement, the subjects stood still beside a cone. They were instructed to walk to the other when signaled by the investigator, go around it to the outer side, and walk back again as fast as possible. They were asked to walk 2.5 complete circuits of the $10-\mathrm{m}$ course, without a break. The stopwatch was used to measure interval times from the start of walking to $40 \mathrm{~m}$ (second return journey), with the stop button pressed at the end of $50 \mathrm{~m}$. The evaluation items recorded were the time required to walk $50 \mathrm{~m}$ and the times required to walk each of laps $1-5$ (all times in seconds). Measurements were performed twice. One lap was defined as the interval distance from one cone to the other cone, which was $10 \mathrm{~m}$ away.

The $10-\mathrm{m}$ walking test was measured with a stopwatch as the time required to walk $10 \mathrm{~m}$ on a flat surface at the maximum walking speed. Measurements were performed twice, and the shortest time (in seconds) was used as the representative time.

Grip strength was measured by using a digital handgrip dynamometer (T.K.K. 5401, Takei Scientific Instruments Co., Ltd., Niigata, Japan). Measurements were performed twice each for the right and left hands, with the subject standing, and the left and right arms hanging down alongside the body. The greatest value was used as the representative value.

The FRT $^{8)}$ was performed by using a functional reach measuring device (T.K.K. 5802, Takei Scientific Instruments Co., Ltd., Niigata, Japan). The subjects were asked to stand with their feet at around shoulder width apart and maintain an arm position with the forearm pronated, the elbow extended, and the shoulder flexed at $90^{\circ}$ when measurements were started. They were then asked to reach as far as possible in front of them. Measurements were performed twice, and the maximum distance (in centimeters) was used as the

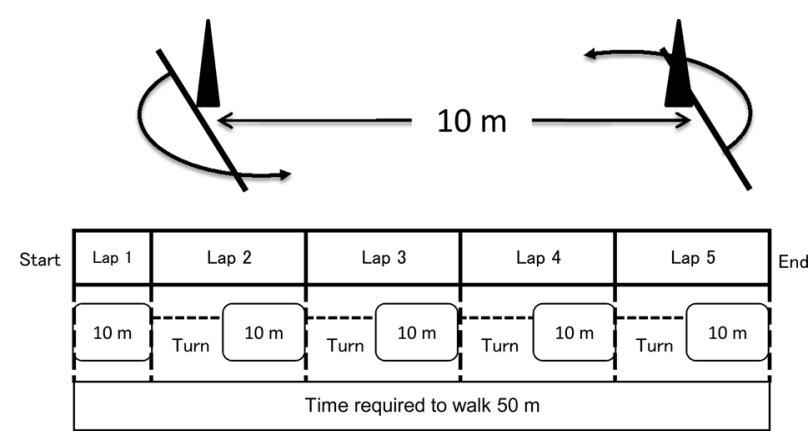

Fig. 1. Diagram of the 50-m walking test measurement model

representative value.

The one-leg standing test was performed by asking the subjects to lift one leg in their own time and by using a stopwatch to measure the time for which they could maintain this position. The measurement was concluded either when the supporting leg moved from its position at the start of measurement or the raised leg touched the floor. Measurements were performed twice each for the right and left legs, and the longest time (in seconds) was used as the representative value.

The TUG test $\left.{ }^{2}\right)$ was performed by using a stopwatch to measure the time taken by the subjects to rise from a sitting position on an armless chair with its seat $40 \mathrm{~cm}$ off the ground, walk around a pole $3 \mathrm{~m}$ in front of the chair, and return to the seated position after being given a signal to start. They were asked to walk as fast as possible. Measurements were performed twice, and the fastest time (in seconds) was used as the representative time.

In terms of statistical analysis, the relative reproducibility of the $50-\mathrm{m}$ walking test and laps $1-5$ was investigated by calculating the intraclass correlation coefficient (ICC) to test the reproducibility of the measurements made by the same investigator. Absolute reliability ${ }^{9}, 10$ ) was tested by means of a Bland-Altman analysis. After the systematic error was determined, measurement error was investigated by calculating the standard error of measurement (SEM) up to the $95 \%$ confidence interval for the minimal detectable change $\left(\mathrm{MDC}_{95}\right)$ as the acceptable rate of error. For the validity of the $50-\mathrm{m}$ walking test, the association with each of the measurement values was investigated in light of the Pearson correlation coefficient for each gender. Next, the partial correlation coefficient was investigated by using age as a control factor for each gender. SPSS Statistics 22 (IBM Corp., Armonk, NY, USA) was used for the ICC calculation and correlation analysis, and R 2.8.1 was used for the BlandAltman analysis, SEM, and $\mathrm{MDC}_{95}$ calculations. The level of significance was set at $\mathrm{p}<0.05$.

\section{RESULTS}

Table 1 shows the results of the 50-m walking test and laps $1-5$ for the 19 subjects. The ICC $(1,1)$ for the 50 -m walking test was 0.97 . In the Bland-Altman analysis, we found no systematic error. The SEM was $1.5 \mathrm{~s}$, and the $\mathrm{MDC}_{95}$ was $3.1 \mathrm{~s}$ (Table 1). 
Table 1. ICCs for the 50-m walking test and laps 1-5 (n=19)

\begin{tabular}{|c|c|c|c|c|c|c|c|c|c|c|}
\hline & \multirow{2}{*}{\multicolumn{2}{|c|}{$\begin{array}{c}\text { Gait speed (s) } \\
(\text { Mean } \pm \text { SD) }\end{array}$}} & \multirow{3}{*}{\multicolumn{2}{|c|}{$\frac{\operatorname{ICC}(95 \% \mathrm{CI})}{\rho}$}} & \multicolumn{3}{|c|}{ Bland-Altman method } & \multirow{3}{*}{$\begin{array}{c}\text { LOA } \\
(\mathrm{s})\end{array}$} & \multirow{3}{*}{$\begin{array}{l}\text { SEM } \\
\text { (s) }\end{array}$} & \multirow{3}{*}{$\begin{array}{c}\mathrm{MDC}_{95} \\
\text { (s) }\end{array}$} \\
\hline & & & & & \multirow{2}{*}{$\begin{array}{c}\text { Fixed bias } \\
95 \% \mathrm{CI} \\
\end{array}$} & \multicolumn{2}{|c|}{ Proportional bias } & & & \\
\hline & Trial 1 & Trial 2 & & & & Regressic & line angle & & & \\
\hline 50-m walking test & $38.9 \pm 6.6$ & $38.4 \pm 6.5$ & 0.97 & $(0.92-0.99)$ & $-0.22-1.31$ & 0.02 & $\mathrm{p}=0.78$ & $-1.25-2.35$ & 1.5 & 3.1 \\
\hline Lap 1 & $6.7 \pm 1.1$ & $6.6 \pm 1.2$ & 0.94 & $(0.85-0.98)$ & $-0.11-0.28$ & -0.08 & $\mathrm{p}=0.36$ & $-0.37-0.54$ & 0.3 & 0.8 \\
\hline Lap 2 & $7.8 \pm 1.3$ & $7.8 \pm 1.3$ & 0.96 & $(0.91-0.99)$ & $-0.12-0.24$ & 0.03 & $\mathrm{p}=0.62$ & $-0.35-0.47$ & 0.3 & 0.7 \\
\hline Lap 3 & $8.0 \pm 1.3$ & $7.9 \pm 1.3$ & 0.95 & $(0.87-0.98)$ & $-0.12-0.30$ & -0.01 & $\mathrm{p}=0.98$ & $-0.41-0.58$ & 0.3 & 0.9 \\
\hline Lap 4 & $8.1 \pm 1.4$ & $8.0 \pm 1.4$ & 0.94 & $(0.84-0.98)$ & $-0.09-0.38$ & -0.04 & $\mathrm{p}=0.64$ & $-0.42-0.70$ & 0.3 & 1.0 \\
\hline Lap 5 & $8.3 \pm 1.5$ & $8.1 \pm 1.3$ & 0.93 & $(0.83-0.97)$ & $-0.07-0.42$ & 0.11 & $\mathrm{p}=0.22$ & $-0.39-0.75$ & 0.3 & 1.0 \\
\hline
\end{tabular}

ICC: intraclass correlation coefficient; CI: confidence interval; LOA: limits of agreement; SEM: standard error measurement; MDC: minimal detectable change; SD: standard deviation

Table 2 shows the means and standard deviations of each measurement in the 50-m walking test and laps 1-5. In the correlation analysis, the 50-m walking test showed a significant correlation with the $10-\mathrm{m}$ walking time $(r=$ $0.89)$, FRT score $(r=-0.79)$, and TUG test score $(r=0.81)$ in the men. The $10-\mathrm{m}$ walking time showed a significant correlation with FRT $(r=-0.81)$ and TUG test scores $(r=$ $0.82)$. In the women, the $50-\mathrm{m}$ walking test score showed a significant correlation with the $10-\mathrm{m}$ walking time $(r=$ $0.83)$, grip strength $(r=-0.60)$, FRT score $(r=-0.60)$, oneleg standing test score $(r=-0.50)$, and TUG test score $(r=$ $0.96)$. The $10-\mathrm{m}$ walking time showed a significant correlation with grip strength $(r=-0.50)$, FRT score $(r=-0.58)$, one-leg standing test score $(r=-0.59)$, and TUG test score $(r=0.81)$. In the partial correlation analysis controlled by age, the $50-\mathrm{m}$ walking test score showed a significant correlation with the 10-m walking time $(r=0.74)$ and TUG test score $(r=0.84)$ in the men. The $10-\mathrm{m}$ walking time showed a significant correlation with FRT $(r=-0.65)$ and TUG test scores $(r=0.78)$. In the women, the 50-m walking test score showed a significant correlation with the 10 -m walking time $(r=0.69)$ and TUG test score $(r=0.92)$. The 10-m walking time showed a significant correlation with TUG test score $(r$ $=0.66$; Table 3 ).

\section{DISCUSSION}

In this study, we investigated the reproducibility and validity of the $50-\mathrm{m}$ walking test for community-dwelling elderly persons. We found that the $50-\mathrm{m}$ walking test was highly reliable and exhibited results significantly correlated with the $10-\mathrm{m}$ walking and TUG test scores. Our findings confirmed that the $50-\mathrm{m}$ walking test is a valid assessment method for walking ability.

The ICC value for the 50-m walking test was high at 0.97 . The ICC values for laps $1-5$, the component elements of the 50-m walking test, were also high at $0.93-0.96$. The Bland-Altman analysis, which was performed to test for systematic error found no systematic error, in either the $50-\mathrm{m}$ walking test or laps $1-5$, confirming that measurement error had no consistent tendency to occur in the measurements in this study. Calculations of the SEM and $\mathrm{MDC}_{95}$ to test for random errors in the measurements resulted in an a SEM of $1.5 \mathrm{~s}$ for the $50-\mathrm{m}$ walking test and $3.1 \mathrm{~s}$ for the $\mathrm{MDC}_{95}$. This
Table 2. Measured values $(n=31)$

\begin{tabular}{llcc}
\hline & & Mean & SD \\
\hline 50-m walking test & (s) & 37.6 & 6.6 \\
Lap 1 & (s) & 6.4 & 1.1 \\
Lap 2 & (s) & 7.6 & 1.4 \\
Lap 3 & (s) & 7.8 & 1.4 \\
Lap 4 & (s) & 7.8 & 1.4 \\
Lap 5 & (s) & 8.0 & 1.5 \\
10-m walking test & (s) & 6.5 & 1.3 \\
Grip strength & (kg) & 27.0 & 8.4 \\
FRT & (cm) & 28.3 & 6.1 \\
One-leg standing test & (s) & 32.0 & 38.8 \\
TUG & (s) & 6.7 & 1.4 \\
\hline
\end{tabular}

FRT: functional reach test; TUG: timed up \& go test; SD: standard deviation

showed that the measurements in the 50-m walking test included a measurement error of $1.5 \mathrm{~s}$ and that the acceptable margin of error was $3.1 \mathrm{~s}$. This means that a measurement variation within $3.1 \mathrm{~s}$ is within the margin of error, whereas an evident change greater than $3.1 \mathrm{~s}$ is caused by a factor other than measurement error. Similarly, the SEM for laps $1-5$ was $0.3 \mathrm{~s}$, and the $\mathrm{MDC}_{95}$ was $0.7-1.0 \mathrm{~s}$. In all the cases, the small size of the measurement error means that it can be judged not to pose a problem in clinical use.

To evaluate the validity of the $50-\mathrm{m}$ walking test as an assessment method for the walking ability of the elderly subjects, we analyzed the correlation of the $50-\mathrm{m}$ walking test scores with the $10-\mathrm{m}$ walking test scores. We found that the $50-\mathrm{m}$ walking time was significantly correlated with the $10-\mathrm{m}$ walking test score. Regarding the relationships of walking ability assessment with the 50-m walking test and $10-\mathrm{m}$ walking time with the respective physical functions, significant correlations with FRT and TUG test scores were observed for both the 50-m walking test score and $10-\mathrm{m}$ walking time in the men. A significant correlation was not observed between grip strength and one-leg standing test score. In the women, both the 50-m walking test score and $10-\mathrm{m}$ walking time showed a significant correlation with grip strength, FRT score, one-leg standing test score, and TUG test score. The partial correlation analysis with age as a 
Table 3. Correlation analysis between the measurement items

\begin{tabular}{|c|c|c|c|c|c|c|c|c|}
\hline & \multicolumn{4}{|c|}{ Male $(n=12)$} & \multicolumn{4}{|c|}{ Female $(n=19)$} \\
\hline & \multicolumn{8}{|c|}{$50-\mathrm{m}$ walking test $10-\mathrm{m}$ walking test $50-\mathrm{m}$ walking test $10-\mathrm{m}$ walking test } \\
\hline 10 -m walking test & 0.87 & $* *$ & & & 0.83 & ** & & \\
\hline Grip strength & -0.39 & & -0.54 & & -0.60 & $* *$ & -0.50 & * \\
\hline FRT & -0.79 & ** & -0.81 & ** & -0.60 & $* *$ & -0.58 & ** \\
\hline One-leg standing test & -0.43 & & 0.01 & & -0.50 & $*$ & -0.59 & $*$ \\
\hline TUG & 0.82 & ${ }^{* *}$ & 0.87 & $* *$ & 0.96 & $* *$ & 0.81 & $* *$ \\
\hline \multicolumn{9}{|c|}{$\begin{array}{l}\text { Pearson correlation coefficient: }{ }^{*} \mathrm{p}<0.05 ; * \mathrm{*} p<0.01 \text {. } \\
\text { FRT: functional reach test; TUG: timed up and go test }\end{array}$} \\
\hline & \multicolumn{4}{|c|}{ Male $(\mathrm{n}=12)$} & \multicolumn{4}{|c|}{ Female $(n=19)$} \\
\hline & \multicolumn{8}{|c|}{$50-\mathrm{m}$ walking test $10-\mathrm{m}$ walking test $50-\mathrm{m}$ walking test $10-\mathrm{m}$ walking test } \\
\hline 10 -m walking test & 0.74 & $*$ & & & 0.69 & $* *$ & & \\
\hline Grip strength & -0.01 & & -0.15 & & -0.47 & & -0.32 & \\
\hline FRT & -0.60 & & -0.65 & $*$ & -0.20 & & -0.28 & \\
\hline One-leg standing test & -0.10 & & 0.26 & & -0.06 & & -0.34 & \\
\hline TUG & 0.84 & ** & 0.78 & ** & 0.92 & ** & 0.66 & ** \\
\hline
\end{tabular}

Partial correlation coefficient (controlling for age): ${ }^{*} \mathrm{p}<0.05 ;{ }^{* *} \mathrm{p}<0.01$.

control factor maintained the significant correlative relationship between the TUG test score and both the $50-\mathrm{m}$ walking test score and 10-m walking time for both the men and women. In a previous study ${ }^{6}$ ) that evaluated healthy elderly men, a significant correlation was observed between the 50-m walking test score and physical function, thus suggesting that the 50-m walking test is also reflective of balancing ability, which is dissimilar to the results of the present study. One conceivable reason for this is that in the prior study, the impact of age was not taken into account. In light of these facts, the 50-m walking test score was confirmed to be a valid method of assessment, making it possible to ascertain walking ability in the elderly.

Our findings confirm the reproducibility of the $50-\mathrm{m}$ walking test, with a maximum measurement error of only approximately $3 \mathrm{~s}$. We also confirmed that the test is useful as an assessment method for walking ability of communitydwelling elderly persons. Furthermore, in light of the results of the present study, the 50-m walking test is possibly affected by aging. Therefore, a greater number of subjects should be included in future studies, and age-specific reference values among elderly persons should be investigated. In addition, as the subjects for the investigation of reliability were only women, the results of the present study might not be applicable to men. Therefore, whether or not the results of the present study can be applied to men needs to be examined.

\section{REFERENCES}

1) Potter JM, Evans AL, Duncan G: Gait speed and activities of daily living function in geriatric patients. Arch Phys Med Rehabil, 1995, 76: 997-999. [Medline] [CrossRef]

2) Podsiadlo D, Richardson S: The timed "Up \& Go": a test of basic functional mobility for frail elderly persons. J Am Geriatr Soc, 1991, 39: 142-148. [Medline]

3) Steffen TM, Hacker TA, Mollinger L: Age- and gender-related test performance in community-dwelling elderly people: Six-Minute Walk Test, Berg Balance Scale, Timed Up \& Go Test, and gait speeds. Phys Ther, 2002, 82: 128-137. [Medline]

4) Bohannon RW: Comfortable and maximum walking speed of adults aged 20-79 years: reference values and determinants. Age Ageing, 1997, 26: 15-19. [Medline] [CrossRef]

5) Hardy SE, Perera S, Roumani YF, et al.: Improvement in usual gait speed predicts better survival in older adults. J Am Geriatr Soc, 2007, 55: 17271734. [Medline] [CrossRef]

6) Hachiya M, Murata S, Otao H, et al.: Development of a new gait assessment scale for the elderly examining the validity of a $50 \mathrm{~m}$ walk test. Jpn J Health Promot Phys Ther, 2014, 4: 83-86 (in Japanese). [CrossRef]

7) Buchner DM, Larson EB, Wagner EH, et al.: Evidence for a non-linear relationship between leg strength and gait speed. Age Ageing, 1996, 25: 386-391. [Medline] [CrossRef]

8) Duncan PW, Weiner DK, Chandler J, et al.: Functional reach: a new clinical measure of balance. J Gerontol, 1990, 45: M192-M197. [Medline] [CrossRef]

9) Yoshida K, Isoya R, Ejiri H, et al.: Measurement errors of a test to determine the scapular position using a tape measure. J Phys Ther Sci, 2011, 23: 851-854. [CrossRef]

10) Shimoi T: The Absolute reliability of evaluation. Rigakuryoho Kagaku, 2011, 26: 451-461 (in Japanese). [CrossRef] 